\title{
PCDD/F Formation from Heterogeneous Oxidation of Wood Pyrolysates
}

\author{
NIGEL W. TAME, BOGDAN Z. DLUGOGORSKI, and ERIC M. KENNEDY \\ Process Safety and Environment Protection Research Group \\ School of Engineering \\ The University of Newcastle, Callaghan, NSW 2308, Australia \\ Email: Bogdan.Dlugogorski@newcastle.edu.au
}

\begin{abstract}
This paper examines the formation of polychlorinated dibenzo-p-dioxins and polychlorinated dibenzofurans (PCDD/F) during oxidative pyrolysis of wood. Model lignocellulosic compounds and fractions isolated from wood serve to generate volatiles which then interact with copper-loaded surrogate ash to produce PCDD/F. The measurements indicate a preference for the formation of PCDF over PCDD in all experiments. Lignin yields considerably more PCDD/F than the carbohydrates, in agreement with the previous measurement in experiments performed under inert conditions [Tame, Dlugogorski, Kennedy, Conversion of Wood Pyrolysates to PCDD/F, Proc. Combust. Inst. 32, submitted]. The ratio of PCDD to PCDF varies according to the chemical structure of the feed; with carbohydrates demonstrating greater relative propensity for PCDF than lignin. The lignin monomers with methyl ether subsitituents (i.e., vanillin and syringol) produce less PCDD/F than those without (i.e., catechol and $p$-hydroxybenzaldehyde). Ensuing experiments, to examine yield of $\mathrm{PCDD} / \mathrm{F}$ as a function of temperature and mass loading of vanillin, reveal the mechanism of heterogeneous condensation of chlorophenols with subsequent chlorination/dechlorination.
\end{abstract}

KEYWORDS: fire chemistry, pollutants from fires, toxicity, dioxins, fires of wood and biomass, treated wood, copper fungicide

\section{INTRODUCTION}

Fires of wood and other biomass involve oxidative decomposition of the solid fuel prior to ignition and inert pyrolysis during flaming combustion. Both processes produce gaseous pyrolysates which may come in contact with copper, present in wood as a fungicide treatment agent. Copper is a particularly potent catalyst for the formation of polychlorinated dibenzo-p-dioxin and polychlorinated dibenzofurans (PCDD/F). The present authors have demonstrated that combustion of treated wood in fires and in smallscale burners (e.g., heating barrels, combustion ovens) may lead to particularly high levels of PCDD/F both in ash and in gaseous emissions [1-4]. We have reported that the oxidative pyrolysis of wood treated with copper boron azole (CBA) could produce PCDD/F emissions as high as $7500 \mathrm{pg} \mathrm{WHO}_{98}-\mathrm{TEQ} / \mathrm{Nm}^{3}$ [2]. Timber treated with preservatives containing metals promoting char smouldering (such as CBA, ammoniacal copper quaternary, or chromated copper arsenate) may yield levels of PCDD/F of even $78 \mathrm{ng}$ $\mathrm{TEQ} / \mathrm{kg}$ ash, via the so-called de novo mechanisms, in comparison to $0.05 \mathrm{ng} \mathrm{TEQ} / \mathrm{kg}$ ash from fires of untreated Pinus radiata [1]. Likewise, the recently introduced organic pesticides, such as tebuconazole or permethrin, normally used in conjunction with copper-based fungicides for treating timber, can produce as much as $1000 \mathrm{ng} \mathrm{TEQ} / \mathrm{g}$ tebuconazole and $5500 \mathrm{ng} \mathrm{TEQ} / \mathrm{g}$ permethrin [4].

Detailed mechanisms of the interaction of various fragments from the pyrolysis and oxidative pyrolysis of lignin and carbohydrates (i.e., cellulose and hemicellulose) with copper remain unknown. Although it is generally well appreciated that this interaction leads to formation of PCDD/F [5]. To obtain further insight into the formation of PCDD/F in fires of treated wood, we have undertaken two experimental programs.

In the first program [6], we have established that under inert conditions, volatiles generated by the pyrolysis of lignin yield much greater amounts of PCDD/F in the presence of copper loaded surrogate ash than those from wood carbohydrates. PCDF were formed in greater proportions than PCDD in all experiments. Lignin generated PCDF under pyrolytic conditions predominantly via formation of dibenzofuran and subsequent chlorination at the 2,3,7,8 positions. Hemicellulose and cellulose were also able to form $\mathrm{PCDD} / \mathrm{F}$ in the presence of surrogate ash despite a lack of aromatic precursors in the original material. Formation from heterogeneous condensation of chlorophenols was more likely for these materials. The 
congener distributions of PCDD/F for wood were visually similar to those produced by volatiles of its lignocellulosic components.

In the present study, wood components and selected model compounds are reacted with a surrogate ash in the presence of oxygen. Model compounds are often used to simulate the thermal decomposition of lignin [7] due to the complex functional heterogeneity of the macromolecule. This amorphous structure results in the loss of mass that is observed over a temperature range, from 120 to over $400{ }^{\circ} \mathrm{C}$ [8]. Monomer units are selected for the oxidative pyrolysis experiments according to their occurrence in different types of lignin, in addition to also being products of incomplete wood combustion. Vanillin (3-methoxy-4-hydroxybenzaldehyde, Fig. 1) represents the thermal degradation of lignin in softwoods, while syringol signifies hardwoods. Hydroxybenzaldyhyde constitutes a common substituent of wood smoke [9], but also models the lignin found in grasses [10]. Catechol serves to simulate the secondary products of lignin pyrolysis.

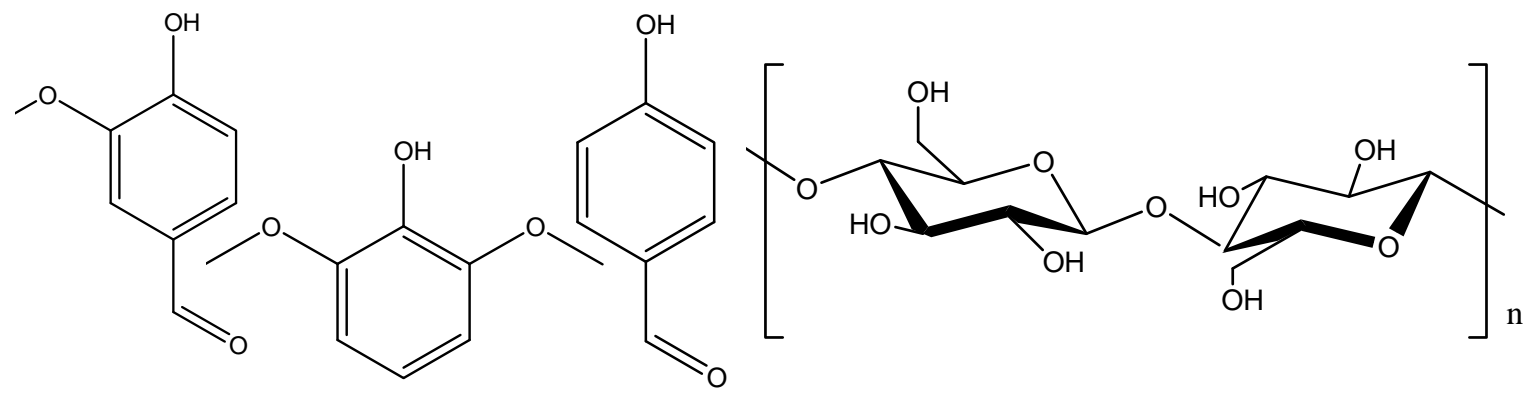

vanillin

syringol

p-hydroxybenzaldehyde

cellulose<smiles>Oc1ccccc1O</smiles>

catechol

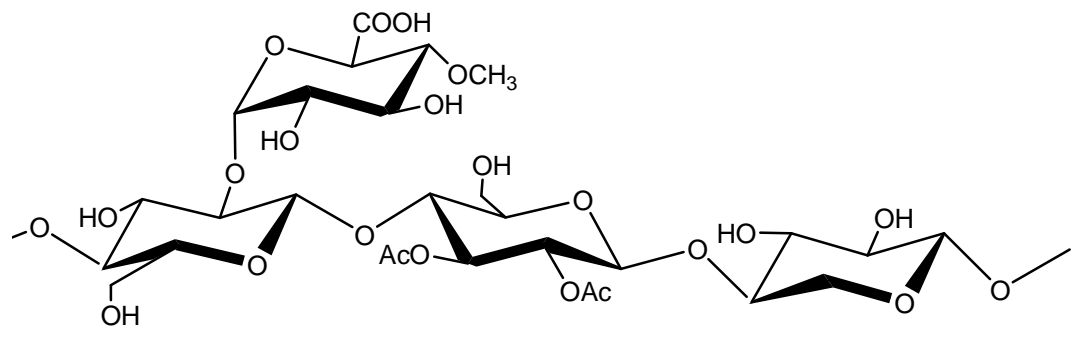

hemicellulose

Fig. 1. Molecular structures of the model wood compounds examined in the present study.

Copper oxide and sodium chloride replaced copper (II) chloride (used in the first program of experiments, [6]) for the oxidative pyrolysis experiments. The latter enabled significant PCDD/F generation under an inert atmosphere, but caused preparation and analytical issues, as a consequence of extremely high levels of $\mathrm{PCDD} / \mathrm{F}$ produced under the oxidation conditions. Hence, $\mathrm{CuO}$ and $\mathrm{NaCl}$ were used in the second program of experiments, with the program involving mainly oxidative pyrolysis of a number of model lignin monomers, selected according to their occurrence in lignin, in addition to being products of incomplete wood combustion. Commercially available cellulose and hemicellulose represent the carbohydrate fractions of wood.

Although PCDD/F formation from chlorophenol [11-13], chlorobenzene [14] and various PAH [15, 16] precursors has been studied, the formation from compounds which are specific to lignin have not been. The mechanism of PCDD/F formation in aqueous wood pulping has been assessed to some extent [17-19], using pulps and synthetic lignin. These demonstrated that lignin monomers are capable of forming considerable levels of PCDD/F under aqueous oxidative conditions. The objective of the present experiments is to investigate the influence of biomass type, heterogeneous oxidation temperature, presence of oxygen and concentration of vanillin in the feed gas on the amount and distribution of PCDD/F. 


\section{EXPERIMENTAL}

\section{Materials}

The experiments involved only ultrahigh purity $\mathrm{O}_{2}$ and $\mathrm{N}_{2}$ gases (99.999\%, Linde). Copper oxide and sodium chloride, the active components in the surrogate ash, were purchased from Hopkin and Williams and Aldrich. Model lingocellulosic compounds originated from Aldrich (vanillin, syringol, hydroxybenzaldehyde, catechol) and Fluka (cellulose, birch hemicellulose).

\section{Apparatus}

A schematic of the experimental arrangement is given in Fig. 2. A borosilicate vaporising vessel was heated within the oven of a gas chromatograph to generate the reactant stream. A temperature was selected such that slow and consistent evaporation/volatilisation of the sample occurred and allowed a consistent, dilute feed concentration. Thermogravimetry was used prior to the experiments to select a suitable temperature for the slow evaporation and to confirm the uniform rate of mass loss.

Streaming $\mathrm{N}_{2}$ through the vessel transferred the volatiles to a quartz tube reactor (12 $\mathrm{mm}$ i.d.) via a heated transfer tube $\left(250 / 330{ }^{\circ} \mathrm{C}\right)$. Oxygen was fed into the end of the reactor, perpendicular to the flow of reactant and $\mathrm{N}_{2}$. The quartz tubular reactor was heated in the three-zone furnace and the reactor output directed to a jacketed XAD adsorbent cartridge and a chilled glass impinger $\left(-10{ }^{\circ} \mathrm{C}\right)$, connected in series for product collection. Flow of $\mathrm{N}_{2}$ and $\mathrm{O}_{2}$ through the system was controlled using mass flow controllers (Brooks Instrument, USA).

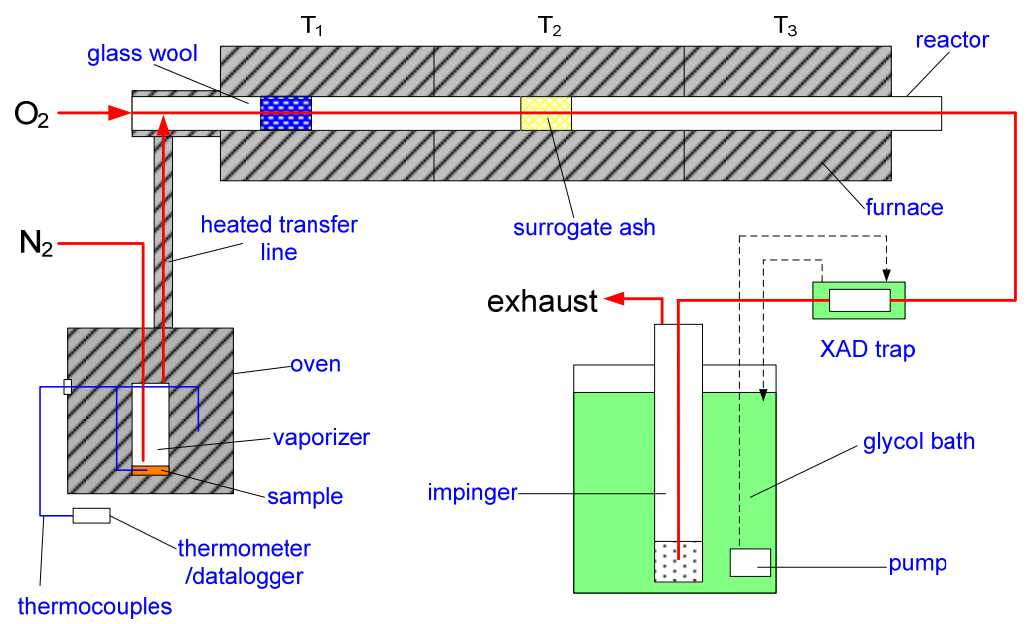

Fig. 2. Set-up of furnace, reactor and product collection with XAD and a solvent-filled impinger.

\section{Methodology}

Table 1 summarises the experimental program. The vaporising vessel housed a reactant sample, with the initial mass loading recorded prior to each experiment. The glass wool positioned and held in place the $\mathrm{CuO} / \mathrm{NaCl} / \mathrm{SiO}_{2}$ surrogate ash $(0.6 \mathrm{~g}$, containing $1 \% \mathrm{Cu}, 1 \% \mathrm{Cl})$. Upon connecting the apparatus together, $\mathrm{N}_{2}$ purged the system for $30 \mathrm{~min}$. This enabled the reactor and heated line to be brought to the reaction temperature under inert conditions. The vaporiser was only heated after thermal equilibrium was achieved in the reactor, and the $\mathrm{O}_{2}$ feed ( $20 \mathrm{ml} / \mathrm{min}, 10 \%$ vol of the total) commenced.

The lignin model reactants (vanillin, hydroxybenzaldehyde, syringol, and catechol) were generated by loading approximately $0.5 \mathrm{~g}$ of solid into the vaporizer and heating the oven to the point of slow and consistent evaporation/volatilisation of the sample. Thermogravimetry was used prior to the experiments to select a suitable temperature for a constant rate of slow evaporation and to confirm a uniform rate of mass loss. The average rate of mass loss for vanillin was $3.5 \pm 0.6 \mathrm{mg} / \mathrm{min}$ ( \pm 1 standard deviation), reasonably consistent with the hydroxybenzaldehyde, syringol, and catechol at 3.5, 6.0 and $4.6 \mathrm{mg} / \mathrm{min}$ respectively. This resulted in a feed concentration of 1- 2.5\% (actual values are provided in Table 1). 
Individual experiment times varied from 30 to $90 \mathrm{~min}$, depending on the PCDD/F yield expected. This method was slightly modified for the carbohydrates (Exps 11 \& 12), in which mass increments of hemicellulose and cellulose were pyrolysed in the vaporizer $\left(320^{\circ} \mathrm{C}\right.$ for both) for 20 minutes to allow complete evolution of volatiles. The $\mathrm{O}_{2}$ reactor supply was ceased and the char replaced with fresh solid. The pyrolysis step was conducted four times per experiment to ensure sufficient PCDD/F were generated for analysis.

Shutting down the experiments involved ceasing $\mathrm{O}_{2}$ supply to the reactor, followed by rapid cooling of the vaporiser, turning off the furnace and disconnecting the reactor. The XAD resin was removed from the adsorbent cartridge and stored with the catalyst plug for PCDD/F analysis. The solvent was sonicated in the impinger, and removed with extensive solvent rinses. The experimental train was rinsed with solvents from the catalyst plug to the impinger for total recovery of the sample. Between experiments the glassware was rinsed with solvents and baked at $450{ }^{\circ} \mathrm{C}$ to minimise cross contamination. A final rinse with acetone and dichloromethane was conducted just prior to running the next experiment.

Table 1. Outline of the experimental program; three runs for Exp. 3.

\begin{tabular}{lllll}
\hline Exp. No. & \multicolumn{1}{c}{ Reactant } & $T_{2}\left({ }^{\circ} \mathrm{C}\right)$ & $\begin{array}{c}\text { In feed } \\
\% \mathrm{wt}\end{array}$ & Notes \\
\hline 1 & vanillin & 300 & $1.5 \pm 0.3$ & \\
2 & vanillin & 350 & $1.5 \pm 0.3$ & \\
3 & vanillin & 400 & $1.5 \pm 0.3$ & \\
4 & vanillin & 450 & $1.5 \pm 0.3$ & \\
5 & vanillin & 500 & $1.5 \pm 0.3$ & \\
6 & vanillin & 350 & $1.5 \pm 0.3$ & no $\mathrm{O}_{2}$ \\
7 & vanillin & 350 & $3.0 \pm 0.3$ & \\
8 & syringol & 350 & $2.5 \pm 0.3$ & \\
9 & hydroxybenzaldehyde & 350 & $1.5 \pm 0.3$ & \\
10 & catechol & 350 & $2.9 \pm 0.3$ & \\
11 & hemicellulose & 350 & & see text \\
12 & cellulose & 350 & & see text \\
\hline
\end{tabular}

\section{PCDD/F Analysis}

The initial solid matrices consisted of surrogate ash and XAD resin for the emission samples. Prior to the commencement of analysis the samples were homogenised, and ${ }^{13} \mathrm{C}_{12}$ labelled surrogate standards (Wellington Labs, Canada) added to all samples before extraction. Solvents used for extraction (GC residue analysis grade, Omnisolv - EM Science, Germany) were toluene, hexane, dichloromethane (DCM) and acetone. Hot soxhlet extraction was performed in an automated soxhlet unit (Buchi, Switzerland) for 6 h. The samples were then evaporated down to less than $1 \mathrm{~mL}$ and solvent exchanged to hexane. If the sample rinses contained excess water and/or polar tars, further extractions on the aqueous layer could be conducted with DCM to maximise sample recovery.

Once in hexane, the samples were acid washed in separating funnels with $98 \% \mathrm{H}_{2} \mathrm{SO}_{4}$ to remove bulk organic contaminants. This was repeated up to 8 times if colour remained in the organic phase. A final rinse with deionised water removed any acid residues. Further clean-up was via an automated PowerPrep $^{\mathrm{TM}}$ unit fitted with disposable acidic/basic silica, basic alumina and activated carbon/celite columns (Fluid Management Systems Inc., USA). The Power-Prep ${ }^{\mathrm{TM}}$ apparatus was utilised at the Dioxin Analysis Unit (DAU) of the National Measurement Institute (NMI) at Pymble (Sydney, Australia). Samples were eluted from the carbon/celite with $200 \mathrm{~mL}$ of toluene and evaporated to dryness under vacuum $(70 \mathrm{mbar}$, $50{ }^{\circ} \mathrm{C}$ ). The extracted PCDD/F were transferred to tapered vials with DCM rinses and concentrated under a stream of $\mathrm{N}_{2}$ at $37^{\circ} \mathrm{C}$ on a heated plate. Additional rinses with DCM during the blowdown helped increase recovery. Once the sample had reduced to a volume of less than $200 \mu \mathrm{L}$, it was transferred with DCM to 2 mL GC vials fitted with $350 \mu \mathrm{L}$ inserts. A final evaporation of the sample was carried out on the hot plate (without $\mathrm{N}_{2}$ ) to 'just dryness'. An additional ${ }^{13} \mathrm{C}_{12}$ labelled "recovery" standard was added in $10 \mu \mathrm{L}$ of 
nonane yielding the final volume for injection. Samples were analysed using a high resolution gas chromatograph/high resolution mass spectrometer, HRGC/HRMS (Finnigan MAT 95XL), at the DAU.

Typical analysis of the PCDD/F was performed using a J\&W DB-5 gas chromatography column (length 60 $\mathrm{m}$, inner diameter $0.25 \mathrm{~mm}$ and film thickness $0.25 \mu \mathrm{m}$ ) or a DB-5ms (J\&W). Subsequent analysis on a $\mathrm{J} \& W$ DB-dioxin column $(60 \mathrm{~m} \times 0.25 \mathrm{~mm} \times 0.15 \mu \mathrm{m})$ enabled isolation and quantification of the 2,3,7,8 congeners that co-elute on the DB-5 column. Native PCDD/F were identified using the relative retention times of the ${ }^{13} \mathrm{C}_{12}$ labelled analogues, in conjunction with the ratio of the integrated peak areas corresponding to the two $\mathrm{m} / \mathrm{z}$ selected for each congener. For example, the peaks for ions $m$ and $m+2$ monitored for TCDF are 303.9016 and 305.8987. The theoretical value for the $m / m+2$ was 0.77 , and the permissible quality control range 0.65 to 0.89 . The values for the other labelled and unlabelled homologue groups are specified in USEPA Method 1613.

PCDD/F were quantified using isotope dilution. This involves relating the amount of native compounds detected to the recovered ${ }^{13} \mathrm{C}_{12}$ labelled PCDD/F to the target native analyte. The initial surrogate standard contained relatively high concentrations of the ${ }^{13} \mathrm{C}_{12}$ PCDD/F relative to the expected level of native compounds in the sample. This allowed quantification of labelled congeners even if low recoveries had occurred, although 40 to $130 \%$ recovery was the target range. The amount of PCDD/F (as a congener or homologue group) was calculated using Eq. 1:

$$
C_{e x}=\frac{\left(A_{1 n}+A_{2 n}\right) C_{l}}{\left(A_{1 l}+A_{2 l}\right) R R}
$$

$C_{\text {ex }}$ in Eq. 1 is the concentration of the congener in the sample extract $(\mathrm{ng} / \mathrm{mL}) . \quad C_{\mathrm{l}}$ is the concentration (ng/mL) of labelled analogue, which is known from the amount of surrogate standard added to the sample prior to preparation. $A_{1}$ and $A_{2}$ are the areas of the primary and secondary $m / z$, with the subscripts ' $n$ ' denoting native and ' $l$ ', ${ }^{13} \mathrm{C}_{12}$ labelled. The relative response to the labelled congener, $R R$, is determined by Eq. 2 using peak areas from a set of calibration solutions containing known amounts of native and masslabelled PCDD/F. $C_{\mathrm{n}}$ is the native congener concentration. Homologue concentrations are calculated by summing up the primary and secondary $\mathrm{m} / \mathrm{z}$ areas for all qualified peaks within a predetermined retention time window and inserting into Eq. 1.

$$
C_{e x}=\frac{\left(A_{1 n}+A_{2 n}\right) C_{l}}{\left(A_{1 l}+A_{2 l}\right) C_{n}}
$$

\section{RESULTS AND DISCUSSION}

The measurements presented in this article assess the generation of PCDD/F from thermal oxychlorination of wood volatiles. A surrogate ash based upon $\mathrm{CuO} / \mathrm{NaCl}$ simulates the residues from burning of CCA impregnated wood, rather than $\mathrm{CuCl}_{2}$. Inorganic chlorine represents the native chlorine in wood, but at a concentration (1\%) sufficient for observable $\mathrm{PCDD} / \mathrm{F}$ formation from small sample sizes. Marine deposition (as in wharf pylons, oyster racks, and coastal domestic constructions) easily achieves this level of chlorine in treated wood. Table 2 summarises the results from Exps. 1-12 and Fig. 3 presents the homologue profiles. Overall yields for the oxidation of wood volatiles over $\mathrm{CuO} / \mathrm{NaCl}$ (present study) fall considerably below those of the pyrolysis as a consequence of a lower chlorination ability of $\mathrm{CuO} / \mathrm{NaCl}$ compared to $\mathrm{CuCl}_{2}[6]$.

The complex nature of lignin means that elucidating the effect of its structural moieties is difficult to achieve. For this reason, we substituted monomeric models for actual lignin to demonstrate the effect of structure on the PCDD/F production. The quantities required of the model compounds were also easily obtained. For carbohydrates, we used cellulose and hemicellulose (xylan) as isolated compounds, e.g., levoglucosan, typically undergo secondary pyrolysis to char, liquid and gas fractions rather than simply evaporating.

The oxidation of lignin model compounds formed greater quantities of PCDD/F per gram of feed than the oxidation of carbohydrate volatiles. The lignin monomers yielded 57-570 ng/g compared to $17 \mathrm{ng} / \mathrm{g}$ for hemicellulose and $9.5 \mathrm{ng} / \mathrm{g}$ for cellulose. The lignin monomers without an $\mathrm{OCH}_{3}$ group (see Fig. 1) produced significantly greater quantities of $\mathrm{PCDD} / \mathrm{F}$, than those with the methyl ether groups. 
Hydroxybenzaldehyde and catechol both generated the equivalent of $20 \times 10^{-6} \mathrm{~mol} \%$ conversion to PCDD and PCDF compared with 2.6 and $3.1 \times 10^{-6} \mathrm{~mol} \%$ for vanillin and syringol. Hemicellulose was capable of greater PCDF production of the two carbohydrate samples; $16 \mathrm{ng} / \mathrm{g}$ to $8.7 \mathrm{ng} / \mathrm{g}$ for cellulose, while both yielded similar amounts of PCDD.

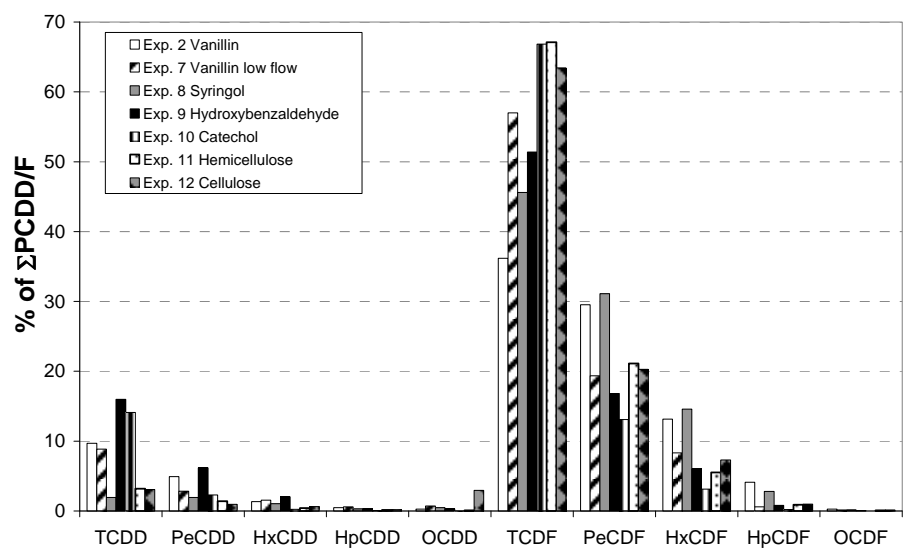

Fig. 3. Homologue distributions comparing the results from wood model compounds at $350{ }^{\circ} \mathrm{C}$.

Table 2. Summary of results from PCDD/F formation during oxidation of wood compounds.

\begin{tabular}{ccccccc}
\hline $\begin{array}{c}\text { Exp. } \\
\text { No. }\end{array}$ & $\begin{array}{c}\text { PCDD/F } \\
\text { ng WHO } \text { 97 }^{-} \\
\text {TEQ/g }\end{array}$ & $\begin{array}{c}\text { PCDD } \\
\text { ng/g }\end{array}$ & $\begin{array}{c}\text { PCDF } \\
\text { ng/g }\end{array}$ & $\begin{array}{c}\text { PCDD/F } \\
\text { ng/g }\end{array}$ & $\begin{array}{c}\text { PCDD/F yield } \\
\text { mol\% } \times 10^{6}\end{array}$ & $\begin{array}{c}\text { PCDD } \\
\text { PCDF }\end{array}$ \\
\hline 1 & 0.11 & 0.80 & 6.8 & 7.6 & 0.33 & 0.117 \\
2 & 1.7 & 9.6 & 48 & 57 & 2.6 & 0.201 \\
3 & $3.3 \pm 0.56$ & $28 \pm 10$ & $98 \pm 12$ & $130 \pm 5$ & 5.8 & $0.300 \pm 0.1$ \\
4 & 5.1 & 22 & 220 & 240 & 11.6 & 0.101 \\
5 & 1.6 & 6.7 & 90 & 97 & 4.6 & 0.075 \\
6 & 0.04 & 0.2 & 1.2 & 1.4 & 0.06 & 0.126 \\
7 & 0.58 & 4.2 & 25 & 29 & 1.4 & 0.171 \\
8 & 1.4 & 3.8 & 63 & 67 & 3.1 & 0.060 \\
9 & 11 & 140 & 410 & 540 & 20 & 0.331 \\
10 & 5.3 & 96 & 480 & 570 & 20 & 0.200 \\
11 & 0.29 & 0.9 & 16 & 17 & - & 0.055 \\
12 & 0.16 & 0.7 & 8.7 & 9.5 & - & 0.084 \\
\hline
\end{tabular}

Oxidation favoured the formation of PCDF rather than PCDD. This is typical of PCDD/F formed in combustion processes, and the oxidation of chlorinated phenol precursors. The carbohydrates (PCDD:PCDF of 0.055 and 0.084) tended towards PCDF more than the majority of the lignin models (0.201 - 0.331). Interestingly the PCDD to PCDF ratio for syringol $(0.060)$ was closer to PCDD/F generated by cellulose and hemicellulose. The structural difference of syringol, which has no substituent para to the $-\mathrm{OH}$, and two ortho $-\mathrm{OCH}_{3}$ groups may be responsible for reducing ability to form PCDD. The two methoxy groups in syringol are noted to induce a steric barrier to the emergence of biphenyl links during the formation of lignin [7].

Only minor PCDD/F formation was observed for vanillin without $\mathrm{O}_{2}$. The yield of $1.4 \mathrm{ng} / \mathrm{g}$ was equivalent to $2 \%$ of the PCDD/F produced by vanillin in the presence of oxygen at $350{ }^{\circ} \mathrm{C}$; compare the measurements of Exps. 2 and 6. It is likely that the condensation and chlorination ability of the $\mathrm{CuO}$ and $\mathrm{NaCl}$ surrogate ash was limited in the inert atmosphere and the temperature too low for significant vanillin dimerisation [20]. Inert conditions favour the formation of PCDD from phenols. However, the ratio of PCDD to PCDF of 0.126 did not vary outside the range of the experiments in the series suggesting no apparent, alternate pathway. Although condensed aromatics are possible during the pyrolysis of vanillin [20], the presence of oxygen is necessary for significant PCDD/F formation in the present system. 
Experiment 7 investigated the sensitivity of PCDD/F formation via oxidation of vanillin to an increase in feed concentration. The total PCDD/F yield decreased to $29 \mathrm{ng} / \mathrm{g}$, and the PCDD and PCDF ratio remained similar (0.171 compared to 0.201 for Exp. 2) upon raising the concentration of vanillin from 0.26 to $0.52 \%$ vol.

The PCDD and PCDF profiles of the different lignin model compounds favour the tetra homologues, although there are variations (Fig. 3). More chlorination is apparent in the PCDF from the heterogeneous oxidation of vanillin and syringol than those from hydroxybenzaldehyde and catechol. TCDF contributed 64 and $67 \%$ of the total tetra to octa- DD/F for the latter two, opposed to 46 and $36 \%$ for the methoxyphenol compounds allowing greater contributions from the PeCDF, HxCDF and HpCDF.

The variations in PCDD and PCDF yields and ratios for vanillin, syringol, hydroxybenzaldehyde and catechol at $350{ }^{\circ} \mathrm{C}$ indicate that monomer substitutions are important in the formation mechanisms. Changes in structure of the lignin models also lead to differences in homologue distributions suggesting chlorine substitution varied during formation. Extrapolating these observations back to fire situations suggests that biomass fuels that are based upon lignin without methoxy groups, like grasses and straw, may have the potential to form higher PCDD/F based upon the structure of their lignin. Obviously additional consideration must be given to the pyrolytic and combustion environment and the higher ash and chlorine of some lignocellulosics.

The conversion of characteristic pyrolysates of different biomasses to PCDD and PCDF may contribute to discrepancies observed in emission factors and homologue distributions [21]. Significant variations in PCDD/F emissions from different biomass sources can be found in the published literature, even when combustion conditions such as fuel density are controlled [22]. Launhardt and Thoma [23] demonstrated much higher PCDD/F and chlorophenol emissions during the combustion of wheat straw and hay compared to spruce wood. Although the grasses contained higher quantities of chlorine, the evolved PCDD/F did not correlate with $\mathrm{HCl}$ emissions and the authors noted that the high variability in results indicated that other factors were present. The variation in phenol substitutions which more easily formed PCDF may have contributed to their observations. The greater ease of PCDD/F formation from less substituted wood phenols may be relevant when fire conditions change the product ratios from, for example, syringols and vanillins to benzaldehydes.

Mechanistic details cannot be elucidated without additional experimental or simulation data. However, a discussion of analogous systems and the results of the present investigation can highlight intermediates for future examination. Lignin model compounds oxidised via aqueous bleaching conditions show a similar dependence of PCDD/F formation on structure [17]. Polymers of coniferyl alcohol (representing softwood lignin and structurally similar to vanillin) were far less prolific than similar compounds of coumaryl alcohol (prominent in grass lignin). PCDF were significantly favoured over PCDD and the homologue profiles were consistent with those from Exps. 1-12 exhibited in Fig. 3; i.e., lower chlorinated groups providing the greatest contributions.

Bleaching conditions have been also used to simulate direct chlorination of lignin models. Chlorine substitution onto catechol yields 4-chlorocatechol, 3,4-dichlorocatechol and 3,4,5-trichlorocatechol in only minor amounts relative to the chlorophenols, which are the product of $\mathrm{OH}$ replacement [24]. Syringol and guaiacol also yield chlorophenols via similar aqueous oxychlorination in addition to $\mathrm{Cl}$ substituted methoxyphenols. Therefore the efficacy for PCDD/F production may be considered to occur via condensation of pre-chlorinated monomers and to depend on the ability of the monomers to yield chlorophenols prior to dimerisation.

Oxidative coupling of vanillin molecules produces divanillin (Fig. 4); a dihydroxybiphenyl substituted with methoxy groups at the 2,2' positions. Divanillin is the result of carbon-carbon coupling similar to the condensation of phenols during formation of PCDF. PCDF observed in Exps. 1-5 may be also produced by the substitution of the methoxy groups with $\mathrm{Cl}$ and and loss of $\mathrm{H}_{2} \mathrm{O}$.

The greater PCDD/F yield from phenolic lignin compounds over those of carbohydrate fractions is unsurprising. Hemicellulose and cellulose do not contain aromatic substituents, although reasonable yields of PCDD/F were observed nonetheless. In the pyrolysis section, we established that these carbohydrates are capable of generating volatile aromatic compounds such as naphthalene, phenol and benzene upon charring. PCDF is then possible via oxidisation and substitution with chlorine. Notably the carbohydrates 
gave the highest values for the PCDD:PCDF in the series of heterogenous pyrolysis experiments, but the lowest during oxidation. Oxidative coupling of single ring aromatics could have been responsible for the shift.<smiles>COc1cc(C=O)cc(-c2cc(C=O)cc(OC)c2O)c1O</smiles>

Fig. 4. Divanillin - a dimer of vanillin formed during oxidation.

\section{Impact of Oxidation Temperature}

We further investigated the oxidation of vanillin over surrogate ash between 300 and $500{ }^{\circ} \mathrm{C}$. The production of PCDD/F peaked at $450{ }^{\circ} \mathrm{C}$ (Fig. 5), indicating the optimal temperature for dioxin formation is between 400 and $500{ }^{\circ} \mathrm{C}$. This trend follows the formation of PCDF, since the yield of PCDF greatly exceeds that of PCDD. The experimental results also indicate the maximum production of PCDD appears near $400{ }^{\circ} \mathrm{C}$. Both temperatures fall inside the thermal window for the formation of PCDD/F from the heterogeneous oxidation of mixtures of chlorophenols [25].

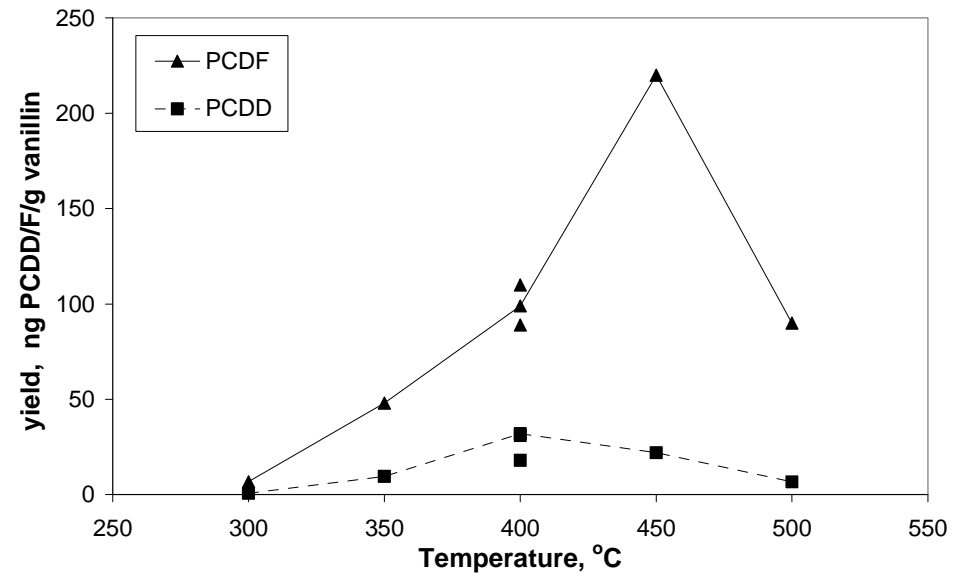

Fig. 5. PCDD and PCDF yields from the heterogeneous oxidation of vanillin between 300 and $500{ }^{\circ} \mathrm{C}$.

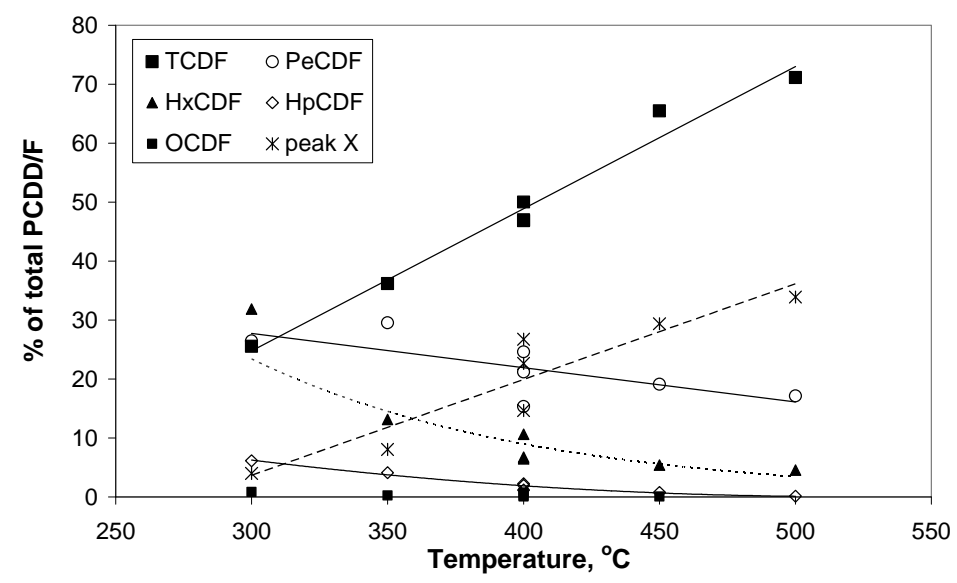

Fig. 6. PCDF homologues as a function of temperature for the oxidation of vanillin. 
PCDF, at low levels of chlorination, dominate the homologue profiles, at all temperatures investigated in this study. PCDF contributions shift increasingly towards TCDF with increasing temperature (Fig. 6), with decreasing trends in the formation of HpCDF, HxCDG, and PeCDF decrease. The shift infers a pathway consisting of rapid chlorination (or condensation of chlorinated precursors) proceeding to dechlorination which accelerates as temperature rises.

As illustrated in Fig. 7, one peak in the TCDF chromatogram emerged as the favoured product(s) as temperature increased, accounting for $34 \%$ of the total PCDD/F at $500{ }^{\circ} \mathrm{C}$. In fact this peak was notable in the PCDD/F resulting from all the oxidation experiments and is likely a TCDF congener preferred by the dechlorination of higher homologues. Typical dechlorination of OCDF indicates that this could be congener(s) substituted in the 4 and 6 positions [22].

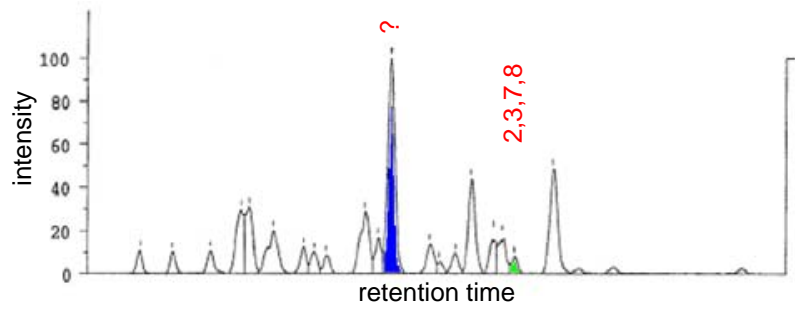

(i)

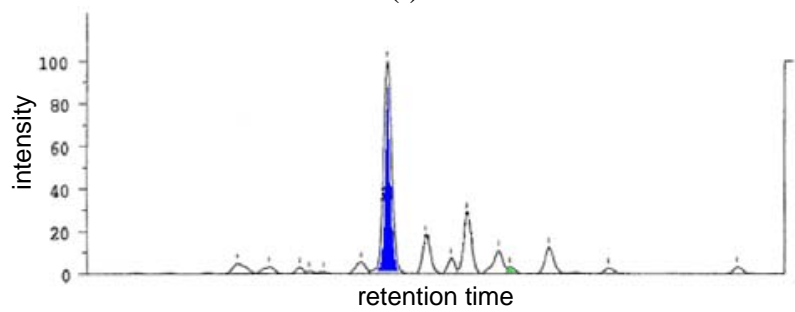

(ii)

Fig. 7. TCDF chromatograms resulting from the heterogeneous oxidation of vanillin at (i) $350{ }^{\circ} \mathrm{C}$ and (ii) $500^{\circ} \mathrm{C}$.

Figure 8 demonstrates that the contribution of the 1,2,3,6,7,8-HxCDF congener rises to $30 \%$ of the total HxCDF at the expense of the 1,2,3,4,6,8- 1,3,4,6,7,8- and 1,2,4,6,7,8-HxCDF. In addition, a peak that is likely the $1,2,3,6,7$ or $1,2,6,7,8$ is the most prominent of the PeCDF. A further loss of chlorine leaves several TCDF congeners possible (Fig. 7), making a conclusive identification difficult without an assignment of the congeners on the db-5ms chromatography column. Figure 7 demonstrates the shift towards the unidentified tetrachlorodibenzofuran peak with increasing temperature.

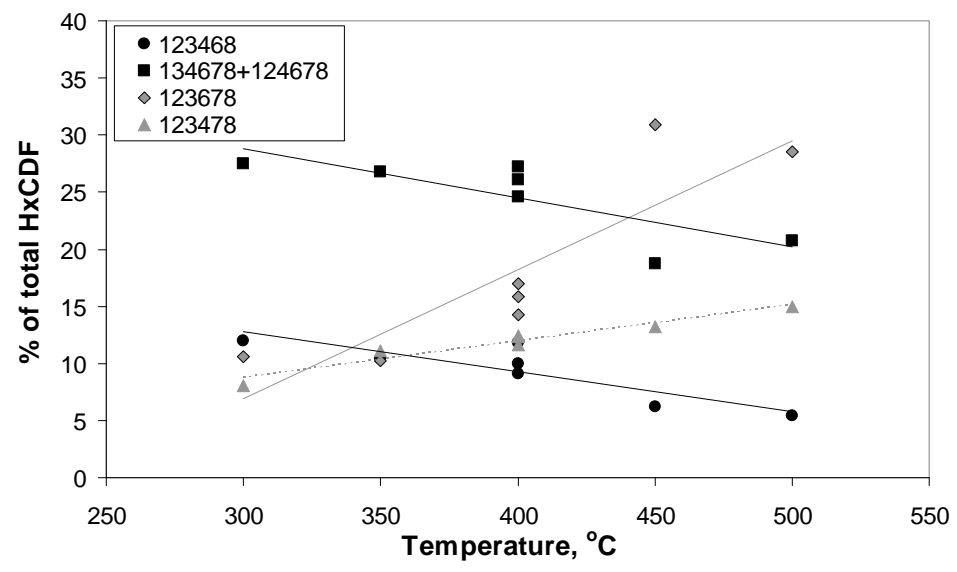

Fig. 8. HxCDF congeners as a function of the vanillin oxidation temperature; lines are provided for the reader to follow the measurements, lines do not represent least square fits. 
The fractional distribution of PCDD homologues in the amount of PCDD product remains approximately constant, independent of the reaction temperature (see Fig. 9). The maximum yield of PCDD between 350 and $450{ }^{\circ} \mathrm{C}$ correlates with peaks in oxychlorination of phenol and condensation of CPs, substituted with at least one ortho chlorine [13]. The CP examined typically include 2,3-DCP, 2,3,4-TCP, 2,3,5-TCP, 2,3,6TCP and 2,3,4,5-TeCP owing to their prevalence in the offgas of municipal waste incinerators. These compounds are also the preferred products of the oxychlorination of guaiacols [24].

The temperature of oxidation influenced the distributions of TCDD congeners. Higher temperatures favoured 1,2,8,9-TCDD, which accounted for $25 \%$ of the total TCDD congeners at $500{ }^{\circ} \mathrm{C}$ compared to $3 \%$ at $300{ }^{\circ} \mathrm{C}$ (Fig. 10). Visually, neither TCDD pattern resembled those from established empirical and theoretical mechanisms [26]: municipal waste incineration emissions tend towards 1,3 substituted congeners (early relative retention time), as does condensation of 2,4,6-TCP [13]. Rather, oxidation temperatures of up to $400{ }^{\circ} \mathrm{C}$ (maximum PCDD formation) resulted in an evenly distributed contributions (Fig. 10(i)), whereas at 450 and $500{ }^{\circ} \mathrm{C}$ the TCDD pattern shifted toward congeners characterised by higher retention times, particularly 1,2,8,9-TCDD; as in Fig. 10(ii).

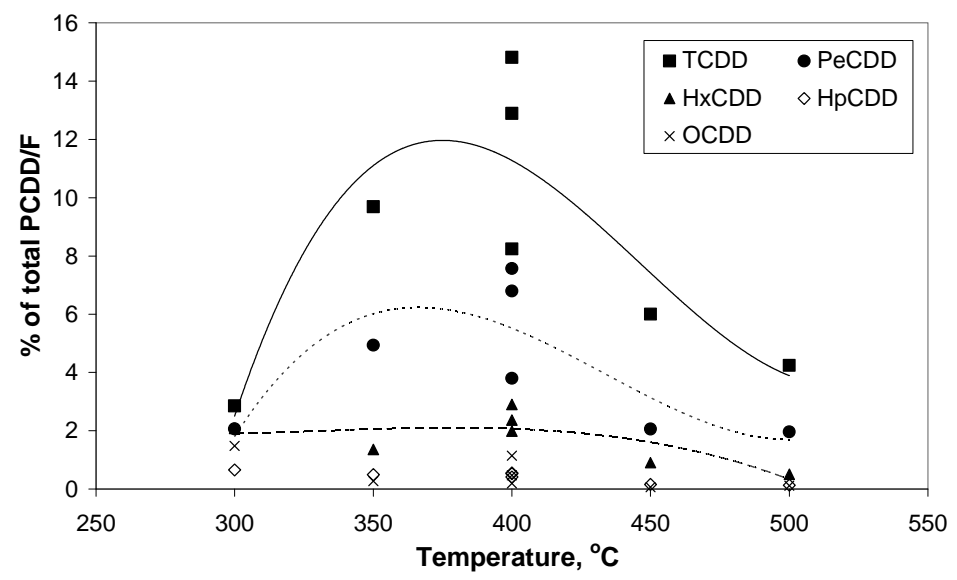

Fig. 9. PCDD homologues as a function of temperature for the oxidation of vanillin; lines are provided for the reader to follow the measurements, lines do not represent least square fits.

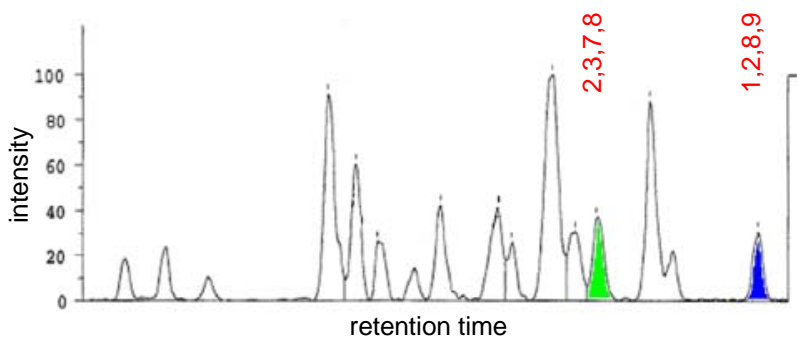

(i)

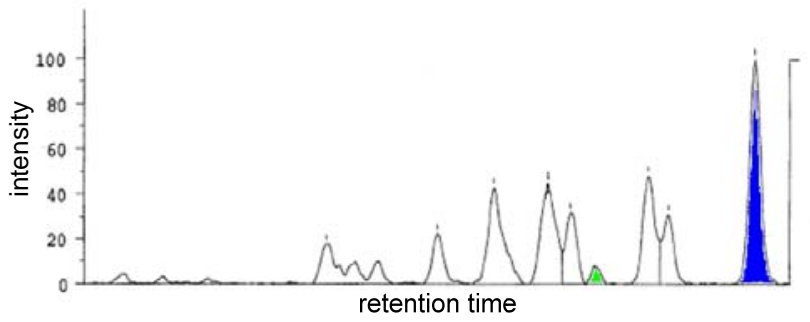

(ii)

Fig. 10. TCDD chromatograms for the heterogeneous oxidation of vanillin at (i) $350{ }^{\circ} \mathrm{C}$, and (ii) $500{ }^{\circ} \mathrm{C}$. 


\section{CONCLUSIONS}

Lignin compounds generated much greater quantities of PCDF and PCDD than carbohydrates during oxidation over a copper-loaded surrogate ash. PCDF were the preferred products in all experiments. Coupling of chlorophenols is also the likely route for production of PCDD/F during the oxidation of wood compounds in the presence of surrogate preservative-treated wood ash. Model lignin monomers without methoxy substituents yield greater amounts of PCDD/F. The difference in ability to yield PCDD/F contributes to the variations in emissions from different types of biomass. Previous literature demonstrates that aqueous oxychlorination of lignin monomers, such as catechol, guaiacols and syringols, can yield dimers, and formation of chlorophenols via the substitution of functional groups is preferred over chlorine substitution of hydrogen.

Vanillin generated a maximum yield of PCDF at $450{ }^{\circ} \mathrm{C}$. This temperature correlates with precursor formation of $\mathrm{PCDD} / \mathrm{F}$ and the homologue profiles revealed a preference for dechlorination with rising temperature. A shift in congeners above the temperature of maximum formation was apparent for PCDD. Congener patterns did not necessarily align with the 4,6 substitution pattern that is typical for loss of chlorine from OCDF. One TCDF congener was clearly favoured (34\% of the total PCDD/F at $\left.500{ }^{\circ} \mathrm{C}\right)$ but could not be identified without a detailed assignment of PCDD/F on the db-5ms chromatography column.

Future investigations should focus on computational and experimental verification of the intermediate species generated by the thermal decomposition of wood under oxidative and inert atmospheres. This will help further elicit pathways to PCDD/F responsible for the emission of these pollutants from fires of wood and other biomass, particularly in the presence of contaminants such as copper-based preservatives.

\section{ACKNOWLEDGEMENT}

This study has been funded by the Australian Research Council.

\section{REFERENCES}

[1] Tame, N.W., Dlugogorski, B.Z., and Kennedy, E.M., (2003) Assessing Influence of Experimental Parameters on Formation of PCDD/F from Ash Derived from Fires of CCA-Treated Wood, Environmental Science and Technology 37: 4148-4156. doi:10.1021/es0304143

[2] Tame, N.W., Dlugogorski, B.Z., and Kennedy, E.M., (2005) PCDD/F Formation in Flaming Combustion, Smoldering and Oxidative Pyrolysis of 'Eco-Friendly' Treated Wood, Proc. Combust. Inst. 30, 1237-1243. doi:10.1016/j.proci.2004.08.008

[3] Tame, N.W., Kennedy, E.M., and Dlugogorski, B.Z., (2005) Formation of Dioxin during Smoldering of CCA Treated Wood Char, Fire Safety Science 8: 1023-1033. doi:10.3801/IAFSS.FSS.8-1023

[4] Tame, N.W., Dlugogorski, B.Z., and Kennedy, E.M., (2007) Formation of Dioxins in Fires of Arsenic-Free Treated Wood: Role of Organic Preservatives, Environmental Science and Technology 41: 6425-6432. doi:10.1021/es0703980

[5] Tame, N.W., Dlugogorski, B.Z., and Kennedy, E.M., (2007) Formation of Dioxins and Furans During Combustion of Treated Wood, Progress in Energy and Combustion Science 22: 384-408. doi:10.1016/j.pecs.2007.01.001

[6] Tame, N.W., Dlugogorski, B.Z., and Kennedy, E.M. Conversion of Wood Pyrolysates to PCDD/F, Proc. Combust. Inst. 32, submitted.

[7] Klein, M.T., “Model Pathways in Lignin Thermolysis”, PhD Dissertation, MIT, 1981.

[8] Shafizadeh, F., (1982) Introduction to Pyrolysis of Biomass, Journal of Analytical and Applied Pyrolysis 3: 283-305. doi:10.1016/0165-2370(82)80017-X

[9] Fine, P.M., Cass, G.R., and Simoneit, B.R.T., (2004) Chemical Characterization of Fine Particle Emissions from the Fireplace Combustion of Wood Types Grown in Midwestern and Western United States, Environmental Engineering Science 21: 387-409. doi:10.1089/109287504323067021 
[10] Han, J. S., and Rowell, J.S., in Paper and Composites From Agro-Based Resources, Rowell, R. M., Young, R. A., and Rowell, J. K. (eds.), CRC Lewis Publishers, Boca Raton, FL, pp. 1997, 83-134.

[11] Zoller, W., and Ballschmiter, K., (1986) "Formation of Polychlorinated Dibenzodioxins and Dibenzofurans by Heating Chlorophenols and Chlorophenates at Various Temperatures", Fresenius' Journal of Analytical Chemistry 323: 19-23. doi:10.1007/BF00531124

[12] Louw, R., and Ahonkhai, S.I., (2002) "Radical/Radical vs Radical/Molecule Reactions in the Formation of PCDD/fs from (Chloro)Phenols in Incinerators, Chemosphere 46: 1273-1278. doi:10.1016/S0045-6535(01)00272-7

[13] Hell, K., Altwicker, E.R., Stieglitz, L., and Addink, R., (2000) Comparison of 2,4,6Trichlorophenol Conversion to PCDD/PCDF on a MSWI-fly Ash and a Model Fly Ash, Chemosphere 40: 995-1001. doi:10.1016/S0045-6535(99)00344-6

[14] Fadli, A., Briois, C., Baillet, C., and Sawerysyn, J.-P., (1999) Experimental Study on the Thermal Oxidation of Chlorobenzene at 575-825 ${ }^{\circ} \mathrm{C}$, Chemosphere 38: 2835-2848. doi:10.1016/S00456535(98)00497-4

[15] Addink, R., Cnubben, P.A.J.P., and Olie, K., (1995) Formation of Polychlorinated Dibenzo-pDioxins/Dibenzofurans on Fly Ash from Precursors and Carbon Model Compounds, Carbon 33: 1463-1471. doi:10.1016/0008-6223(95)00100-R

[16] Wilhelm, J., Stieglitz, L., Dinjus, E., Will, R., (2001) Mechanistic Studies on the Role of PAHs and Related Compounds in PCDD/F Formation on Model Fly Ashes, Chemosphere 42: 797-802. doi:10.1016/S0045-6535(00)00253-8

[17] Hrutfiord, B.F., Negri, A.R., (1992) Chlorinated Dibenzofurans and Dibenzodioxins From Lignin Models, Tappi Journal (August): 129-134.

[18] Buckland, S.J., Hannah, D.J., Taucher, J.A., (1990) The formation of Polychlorinated Dibenzo-pDioxins and Dibenzofurans from the Bleaching of New Zealand Pinus Radiata, Organohalogen Compounds: 219-221.

[19] Hise, R. G., and Wright, B.T., (1990) Formation of Chlorinated Dioxins and Furans from Lignin and Lignin Model Compounds, Chemosphere 20: 1723-1730. doi:10.1016/0045-6535(90)90335-Q

[20] Shin, E.-J., Nimlos, M.R., Evans, R.J., (2001) A Study of the Mechanisms of Vanillin Pyrolysis by Mass Spectrometry and Multivariate Analysis, Fuel 80: 1689-1696. doi:10.1016/S00162361(01)00055-2

[21] Gullett, B. K., Touati, A., (2003) PCDD/F Emissions from Forest Fire Simulations, Atmospheric Environment 37: 803-813. doi:10.1016/S1352-2310(02)00951-2

[22] National Dioxins Program Technical Report No. 1 "Dioxin Emissions from Bushfires in Australia," Australian Government Department of the Environment and Heritage, 2004.

[23] Launhardt, T., Thoma, H., (2000) Investigation on Organic Pollutants from a Domestic Heating System Using Various Solid Biofuels, Chemosphere 40: 1149-1157. doi:10.1016/S00456535(99)00364-1

[24] Michalowicz, J., Duda, W., Stufka-Olczyk, J., (2007) Transformation of Phenol, Catechol, Guaiacol and Syringol Exposed to Sodium Hypochlorite, Chemosphere 66: 657-663. doi:10.1016/j.chemosphere.2006.07.083

[25] Ryu, J.-Y., Mulholland, J.A., (2005) Metal-Mediated Chlorinated Dibenzo-p-Dioxin and Dibenzofuran (CDF) Formation from Phenols, Chemosphere 58: 977-988. doi:10.1016/j.chemosphere.2004.08.084

[26] Iino, F., Imagawa, T., Gullett, B. K., (2000) Dechlorination-Controlled Polychlorinated Dibenzofuran Isomer Patterns from Municipal Waste Incinerators, Environmental Science and Technology 34: 3143-3147. doi:10.1021/es9913131 